\title{
Estimating the carbon fluxes of forests with an individual-based forest model
}

Edna Rödig ${ }^{1 *}$, Andreas Huth $^{1,2,3}$, Friedrich Bohn ${ }^{1}$, Corinna Rebmann ${ }^{1}$ and Matthias Cuntz ${ }^{1,4}$

\begin{abstract}
Background: Capturing the response of forest ecosystems to inter-annual climate variability is a great challenge. In this study, we tested the capability of an individual-based forest gap model to display carbon fluxes at yearly and daily time scales. The forest model was applied to a spruce forest to simulate the gross primary production (GPP), respiration and net ecosystem exchange (NEE). We analyzed how the variability in climate affected simulated carbon fluxes at the scale of the forest model.

Results: Six years were simulated at a daily time scale and compared to the observed eddy covariance (EC) data. In general, the seasonal cycle of the individual carbon fluxes was correctly described by the forest model. However, the estimated GPP differed from the observed data on the days of extreme climatic conditions. Two new parameterizations were developed: one resulting from a numerical calibration, and the other resulting from a filtering method. We suggest new parameter values and even a new function for the temperature limitation of photosynthesis.

Conclusions: The forest model reproduced the observed carbon fluxes of a forest ecosystem quite well. Of the three parameterizations, the calibrated model version performed best. However, the filtering approach showed that calibrated parameter values do not necessarily correctly display the individual functional relations. The concept of simulating forest dynamics at the individual base is a valuable tool for simulating the NEE, GPP and respiration of forest ecosystems.
\end{abstract}

Keywords: Forest model, Temperate forest, Carbon fluxes, Eddy covariance, FORMIND

\section{Background}

Inter-annual climate variations can strongly influence the productivity of forest ecosystems. The heat wave of 2003, for example, caused a reduction of approximately $30 \%$ to the gross primary production (GPP) over Europe (Ciais et al. 2005). This extreme event was followed by several studies to understand ecosystem responses and their underlying mechanisms (e.g., Zaitchik et al. 2006; Granier et al. 2007). Models predict that such extreme events will become more frequent and intense in the future (Meehl and Tebaldi 2004).

However, correctly capturing the responses of an ecosystem to varying climatic conditions with vegetation models is a major challenge (Keenan et al. 2012). In this study, we test the potential of a forest gap model that considers forest structure at the local scale to estimate

\footnotetext{
* Correspondence: edna.roedig@ufz.de

${ }^{1}$ UFZ - Helmholtz Centre for Environmental Research, Permoserstr. 15, 04318

Leipzig, Germany

Full list of author information is available at the end of the article
}

daily carbon fluxes and their response to climate variations in a spruce forest in Germany.

Forest models have a long tradition in ecological research (Botkin et al. 1972; Shugart 1984; Pacala et al. 1993; Köhler and Huth 2004). They have been successfully applied to analyze forest succession, tree species composition and biomass (e.g., Fischer et al. 2016). Capturing the competition between individuals enables these types of models to reproduce reality better than vegetation models which operate at a larger scale (Smith et al. 2001). Traditionally, studies using forest models have focused on forest structure and dynamics, but they often neglected carbon exchange with the atmosphere (Bugmann 2001).

In this study, we used an individual-based forest gap model (FORMIND) that simulates the growth of individual trees by calculating its photosynthesis and respiration (Köhler and Huth 1998). In addition, a soil carbon module is included (derived from Sato et al. 2007). These model characteristics established a base to capture carbon fluxes 
at the ecosystem level, in addition to biomass and treesize distributions.

Up to now, the forest model FORMIND has mainly been used to reproduce the average forest conditions in long-term studies at yearly time scales (Gutiérrez et al. 2009; Fischer et al. 2014; Bohn et al. 2014). The influence of short-term climate variability on individual model processes (GPP and respiration) has not yet been tested. Therefore, we here compared daily simulation output of the forest model with observed eddy covariance data of two spruce forests and analyzed the following two aspects. First, we wanted to test whether the local forest model is generally capable of displaying daily carbon fluxes. Second, we analyzed whether the model processes correctly respond to variable climate inputs. In this context, we evaluated the response of three different model parameterizations. We explored how we can use eddy covariance data to improve the simulation of carbon fluxes with an individualbased forest model. The simulation time also covered the heat wave of 2003 which enabled to include an extreme event in the analyses.

The following questions will guide us through this study: (1) How well does an individual-based forest gap model simulate the daily and yearly carbon fluxes of a temperate forest ecosystem? (2) How can EC data be used to improve the concept of limiting factors in forest gap models?

\section{Methods}

\section{The study sites}

This study focused on a forest site located at Wetzstein Mountain, part of the Thuringian Forest in central-east Germany where measured carbon fluxes and inventory data are available (Wetzstein flux tower, Rebmann et al. 2010). Observed carbon fluxes were derived with the eddy covariance (EC) method, a technique that observes the local carbon flux dynamics of the vegetation and monitors inter-annual changes (Aubinet et al. 1999). The Wetzstein forest is dominated by even-aged Norway spruce (Picea abies) stands on clay loam. In addition, we analyzed another Norway spruce stand at Tharandt, a study site in the Ore Mountains in Germany where ECdata were available (Tharandt Anchor station, Grünwald and Bernhofer 2007). The stand characteristics of both sites are summarized in Table 1.

\section{The forest model FORMIND}

FORMIND (Köhler and Huth 2004; Fischer et al. 2016) is an individual-based forest gap model in which growth is calculated for each tree individually. The approach uses patches to describe the vertical and horizontal forest structures. The main processes of the model include establishment, growth, mortality and competition. Important driving factors are daily means of incoming light
Table 1 Site characteristics for Wetzstein (Rebmann et al. 2010; Martina Mundt, personal communication) and Tharandt (Grünwald and Bernhofer 2007)

\begin{tabular}{lll}
\hline & Wetzstein & Tharandt \\
\hline Location & $50^{\circ} 27^{\prime} \mathrm{N}, 11^{\circ} 27^{\prime} \mathrm{E}$ & $50^{\circ} 57^{\prime} \mathrm{N}, 13^{\circ} 34^{\prime} \mathrm{E}$ \\
Time period & $2003-2008$ & $1999-2004$ \\
Date of inventory & 2004 & 1999 \\
Stand age $(\mathrm{a})$ & 50 & 108 \\
Stand density $\left(\mathrm{ha}^{-1}\right)$ & 410 & $477^{\mathrm{a}}$ \\
Mean stem diameter $(\mathrm{dbh})(\mathrm{m})$ & 0.33 & 0.33 \\
Leaf area index $\left(\mathrm{m}^{2} \cdot \mathrm{m}^{-2}\right)$ & $7.0^{\mathrm{b}}$ & 7.7 \\
Elevation $(\mathrm{m})$ & 792 & 380 \\
Annual mean temperature $\left({ }^{\circ} \mathrm{C}\right)$ & 6.5 & 8.8 \\
Annual mean precipitation $\left(\mathrm{mm} \cdot \mathrm{a}^{-1}\right)$ & 810 & 673 \\
Annual mean PPFD $\left(\mu \mathrm{mol} \cdot \mathrm{m}^{-2} \cdot \mathrm{s}^{-1}\right)$ & 489 & 583 \\
\hline
\end{tabular}

Climatological means were calculated from data obtained during the investigated time period

an April 2002, the number of trees was reduced by approximately $30 \%$ due to

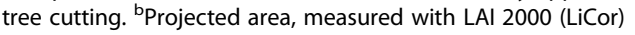

(photosynthetic photon flux density, PPFD), temperature and precipitation (based on a model verison for temperate forests as in Bohn et al. 2014). In this study, the model was applied to an even-aged spruce forest (1 ha). Establishment and mortality were deactivated for the short simulation time of 6 years. A full model description can be found in Fischer et al. (2016) and at www.formind.org.

The model runs with daily variable observed climate inputs of PPFD, day length, temperature and precipitation measured onsite. PPFD and day length serve as the driving forces for forest productivity. The sum of the GPP over all trees thus equals the GPP of the ecosystem. The ecosystem respiration is the sum of the respiration of all trees plus that of the soil and deadwood. The NEE is calculated as the difference between the ecosystem GPP and the ecosystem respiration (Fischer et al. 2014). A positive NEE corresponds to increasing carbon stocks.

\section{Gross primary production}

Photosynthesis is calculated at the leaf level using a light-response function and is then integrated over the entire canopy (Thornley and Johnson 1990). The GPP of an individual tree under optimal climatic conditions (Huth and Ditzer 2000) equals

$$
\begin{aligned}
& \operatorname{GPP}_{\text {ptree }}\left(I_{\text {ind }}(\operatorname{PPFD}(t))\right) \\
& =\frac{p_{\text {max }}}{k} \ln \left\{\frac{\alpha k I_{\text {ind }}(\operatorname{PPFD}(t))+p_{\text {max }}[1-m]}{\alpha k I_{\text {ind }}(\operatorname{PPFD}(t)) e^{-k L A I}+p_{\text {max }}[1-m]}\right\} A_{c} \psi
\end{aligned}
$$

in $\mu \mathrm{mol}\left(\mathrm{CO}_{2}\right) \cdot \mathrm{m}^{-2} \cdot \mathrm{s}^{-1}$, where $p_{\max }\left(\mu \mathrm{mol}\left(\mathrm{CO}_{2}\right) \cdot \mathrm{m}^{-2} \cdot \mathrm{s}^{-1}\right)$ is the maximum photosynthetic rate of the tree species (here, spruce), $\alpha$ is the initial slope of the light-response 
curve $\left(\mu \mathrm{mol}\left(\mathrm{CO}_{2}\right) \cdot \mu \mathrm{mol}\right.$ (photons) $\left.{ }^{-1}\right), k$ is the light extinction factor, and $m$ is the transmission coefficient of the leaves. $I_{\text {ind }}$ is the fraction of the PPFD at daily time step $t$ that reaches the top of the individual tree. $A_{c}\left(\mathrm{~m}^{2}\right)$ is the crown area, and $\psi(\mathrm{s})$ the photosynthetically active period of the time scale. Under non-optimal climatic conditions, $G P P_{\text {ptree }}$ is limited by the available soil water $(S W)$ and temperature (T) (Bohn et al. 2014):

$$
\operatorname{GPP}_{\text {tree }}(t)=\operatorname{GPP}_{\text {ptree }}(t) \cdot \varphi_{S W}(t) \cdot \varphi_{T}(t),
$$

where $\varphi_{S W}$ is the water reduction factor $([0,1])$, and $\varphi_{T}$ the temperature reduction factor $([0,1])$.

The temperature reduction factor $\varphi_{T}$ is derived from the LPJ-model (Sitch et al. 2003) which includes two ramp functions (Gutiérrez et al. 2012):

$$
\begin{aligned}
\varphi_{T}(t)= & \left(1+e^{\frac{2 \ln \left(\frac{0.01}{T_{C O}, l^{-1}}\right)}{T_{\text {cold }}}}\left(0.5\left(T_{C O_{2}, l}+T_{\text {cold }}\right)-T(t)\right)\right)^{-1} \\
& \times\left(1-0.01 e^{\frac{\ln \left(\frac{0.99}{0.01}\right)}{T_{C O}, h^{-T h o t}}}\left(T(t)-T_{\text {hot }}\right)\right)
\end{aligned}
$$

where $T\left({ }^{\circ} \mathrm{C}\right)$ is the daily mean air temperature at time step $t . \quad T_{\mathrm{CO}_{2}, h}, T_{\mathrm{CO}_{2}, l}, T_{\text {cold }}$ and $T_{\text {hot }}\left({ }^{\circ} \mathrm{C}\right)$ are speciesspecific parameters representing the higher and lower temperature limits for $\mathrm{CO}_{2}$ assimilation and the monthly mean air temperatures of the warmest and coldest months when production can still occur.

In this study, we also tested a new temperature reduction curve $\varphi_{T^{*}}{ }^{*}$. It is distributed around the optimal temperature for photosynthesis $T_{\text {opt }}\left({ }^{\circ} \mathrm{C}\right)$ and the width $T_{\text {sig }}\left({ }^{\circ} \mathrm{C}\right)$ (June et al. 2004, reduction of the electron transport rate with $n=2$ ) since Eq. 3 could not be properly fitted to the observed data. We suggest fitting this bell-shaped curve because it only relies on two parameters instead of four parameters (Eq. 3):

$$
\varphi_{T} *(t)=e^{-\left(\frac{T(t)-T_{\text {opt }}}{T_{\text {sig }}}\right)^{n}} .
$$

We use a water reduction factor, $\varphi_{S W}$, as proposed by Granier et al. (1999):

$$
\varphi_{S W}(t)=\left\{\begin{array}{cl}
0 & : S W(t)<S W_{\mathrm{pwp}} \\
\frac{S W(t)-S W_{\mathrm{pwp}}}{S W_{\mathrm{msw}}-S W_{\mathrm{pwp}}} & : S W_{\mathrm{pwp}}<S W(t)<S W_{\mathrm{msw}}, \\
1 & : S W(t)>S W_{\mathrm{msw}}
\end{array}\right.
$$

where $S W_{\text {pwp }}$ is the permanent wilting point, $S W_{\text {msw }}$ $=S W_{\mathrm{pwp}}+0.4\left(S W_{\mathrm{fc}}-S W_{\mathrm{pwp}}\right)$ is the minimum soil water content for maximum photosynthesis, and $S W_{\mathrm{fc}}$ is the field capacity. Available soil water is calculated from the daily precipitation, interception by leaves, above- and below-ground water runoff, and transpiration of trees (Fischer et al. 2014).

\section{Respiration}

The respiration of a tree is the sum of its maintenance respiration, $R_{m}$, and its growth respiration, $R_{g}$, a constant fraction of $\left(G P P-R_{m}\right)$. The maintenance respiration is calculated as follows:

$$
R_{m}(t)=R_{b}(t) \kappa(T(t)),
$$

where $R_{b}$ is a base respiration, a fraction of standing biomass of the tree (Bohn et al. 2014, detailed description in supplementary information A3). $\kappa(T)$ describes the influence of the daily mean air temperature $T$ on respiration (Prentice et al. 1993):

$$
\kappa(T(t))=Q_{10}^{\frac{T(t)-T_{\text {ref }}}{10}},
$$

with constants $T_{r e f}$ and $Q_{10}$ (Bohn et al. 2014).

\section{Field data and data filtering}

We compared the simulation results of the forest model with the EC data of the Wetzstein site (Table 1). For the Wetzstein site, the EC data were pre-processed as described in Rebmann et al. (2010). The net ecosystem exchange (NEE) was gap filled since the data are compared at daily time scales and partitioned into GPP and respiration. We use an algorithm that extrapolates day-time ecosystem respiration from night-time respiration considering temperature sensitivities (Reichstein et al. 2005).

We filtered the EC data to identify days that are affected by specific limitations. Optimal temperature or soil water conditions were defined for days when the daily mean GPP was maximal (98th percentile for the years 2003 to 2008). We assumed that on those days the GPP is not affected by any limitation. The filtered range of the optimal temperature (daily daytime mean) conditions was identified at $7.3{ }^{\circ} \mathrm{C}<T<18.0{ }^{\circ} \mathrm{C}$, and the threshold for non-limiting soil water conditions at $\mathrm{SW}>$ 16.0\%. Optimal light conditions were defined for days when values rise above the monthly 80th percentile. We define night-time as time periods when PPFD $<20 \mu \mathrm{mol}$ $\left(\mathrm{CO}_{2}\right) \cdot \mathrm{m}^{-2} \cdot \mathrm{s}^{-1}$. When we use normalized GPP values in our analyses, we normalize GPP values yearly by its annual 98th percentile.

\section{The model setup}

The forest model was run with daily time steps for three different parameterizations: literature-based (M1), numerically calibrated (M2) and filter-based (M3) parameterizations (Table 2). The literature-based parameterization (M1) is based on Bohn et al. (2014) for a spruce forest where the parameter values are derived from inventory data and the literature. The soil parameter values were adapted to the 
Table 2 Model parameter values for the literature-based (M1) with references (ref.), calibrated (M2) and filter-based (M3) model version

\begin{tabular}{|c|c|c|c|c|c|}
\hline \multicolumn{2}{|c|}{ Parameter } & M1 & Ref. & M2 & M3 \\
\hline \multicolumn{6}{|c|}{ Productivity } \\
\hline$p_{\max }$ & max. photoproducitvity of leaf $\left(\mu \mathrm{mol}\left(\mathrm{CO}_{2}\right) \cdot \mathrm{s}^{-1} \cdot \mathrm{m}^{-2}\right)$ & 8.9014 & (Sonntag 1998; Bohn et al. 2014) & 5.67 & 10.98 \\
\hline a & slope of light response curve $\left(\mu \mathrm{mol}\left(\mathrm{CO}_{2}\right) \cdot \mu \mathrm{mol}(\text { photons })^{-1}\right)$ & 0.0402 & (Sonntag 1998; Bohn et al. 2014) & 0.15 & 0.08 \\
\hline \multicolumn{6}{|c|}{ Temperature } \\
\hline$T_{\mathrm{CO}_{2}, l}$ & min. temperature for photosynthesis $\left({ }^{\circ} \mathrm{C}\right)$ & -2.0 & (Sitch et al. 2003; Bohn et al. 2014) & -7.82 & - \\
\hline$T_{\mathrm{CO}_{2}, h}$ & max. temperature for photosynthesis $\left({ }^{\circ} \mathrm{C}\right)$ & 38.0 & (Sitch et al. 2003; Bohn et al. 2014) & 31.59 & - \\
\hline$T_{\text {hot }}$ & mean temperature of warmest month $\left({ }^{\circ} \mathrm{C}\right)$ & 18.9 & (Sitch et al. 2003; Bohn et al. 2014) & 12.0 & - \\
\hline$T_{\text {cold }}$ & mean temperature of coldest month $\left({ }^{\circ} \mathrm{C}\right)$ & 10.0 & (Sitch et al. 2003; Bohn et al. 2014) & 8.47 & - \\
\hline$T_{\mathrm{opt}}$ & optimal temperature for photosynthesis $\left({ }^{\circ} \mathrm{C}\right)$ & - & - & - & 14.22 \\
\hline$T_{\text {sig }}$ & width of new temperature curve $\left({ }^{\circ} \mathrm{C}\right)$ & - & - & - & 12.83 \\
\hline$Q_{10}$ & constant for temperature-dependent respiration & 2.3 & (Piao et al. 2010; Bohn et al. 2014) & 1.52 & 1.52 \\
\hline$T_{\text {ref }}$ & Reference temperature $\left({ }^{\circ} \mathrm{C}\right)$ & 10.1 & (Bohn et al. 2014) & 12.61 & 15.06 \\
\hline \multicolumn{6}{|l|}{ Water } \\
\hline$S W_{\text {pwp }}$ & permanent wilting point (vol-\%) & 19.7 & (Maidment 1993) & 14.0 & 9.5 \\
\hline$S W_{\mathrm{fc}}$ & field capacity (vol-\%) & 31.8 & (Maidment 1993) & 40.0 & 20.7 \\
\hline
\end{tabular}

clay loam soil type as in Maidment (1993). The calibrated parameterization (M2) is based on parameters derived from a numerical calibration against the NEE, GPP and respiration data (Lehmann and Huth 2015, see Additional file 1 for details). The filter-based parameterization (M3) arose from filtering the EC data (same data as used for calibration of M2) for optimal climatic conditions (see Field data and data filtering) to isolate individual processes. Model functions were directly fitted through filtered data to derive new parameter values and a new temperature reduction curve (Eq. 4).

All model setups were initialized according to the inventory data for Wetzstein and Tharandt (Table 1). Trees were spread equally over the 25 patches of the 1 ha model area (at Wetzstein, 410 stems.ha ${ }^{-1}$ with a mean stem diameter of $0.33 \mathrm{~m}$ ). The deadwood pool was filled with $4.14 \mathrm{tC} \cdot \mathrm{ha}^{-1}$ (Wetzstein inventory, personal communication from Martina Mund, University of Goettingen). The fastdecomposing soil stock was initialized with $2.0 \mathrm{tC} \cdot \mathrm{ha}^{-1}$, and the slow-decomposing soil stock with $1.5 \mathrm{tC} \cdot \mathrm{ha}^{-1}$ (means in the climax stage of long-term simulations). The simulation period at the Wetzstein site was from 2003 to 2008 and at Tharandt from 1999 to 2004. All model simulations were deterministic since none of the model setups included recruitment or stochastic mortality.

\section{Results}

\section{Simulation of daily carbon fluxes at Wetzstein forest}

The measured and modeled (parameterization M1) GPP and respiration at Wetzstein forest for the dry year 2003 are shown in Fig. 1. The forest model performed well for daily GPP. It reproduced the seasonal cycle, and the daily fluctuations showed similar magnitudes to those observed. Differences were observed during times of low soil water availability, very low and high temperatures and bright days. In late summer (July-September), the simulated respiration diverges from the observational data. In general, simulated respiration shows stronger fluctuations than the observed respiration.

\section{Simulation of carbon fluxes at Wetzstein forest for three different parameterizations}

We compared the simulations of all three model versions with the observed fluxes at Wetzstein at the daily time scale (Table 3, Fig. 2). The correlation is best for the numerically calibrated parameterization (M2), closely followed by the filter-based parameterization (M3). Simulated respiration correlates with the observed values with an $R^{2}$ of $0.44-0.54$; NEE with an $R^{2}$ of $0.63-0.66$. Simulated and observed GPP values match best with an $R^{2}$ of $0.73-0.82$. High GPP values above $30 \mathrm{tC} \cdot \mathrm{ha}^{-1} \cdot \mathrm{a}^{-1}$ can only be reached with the filter-based parameterization (M3, Fig. 2).

In a second step, we calculated annual GPP, NEE and respiration for the Wetzstein forest (Fig. 3a). The simulated annual NEE values fit the observed annual values best for the calibrated parameterization (M2, deviation from observed data by $3.5 \%$ for average values throughout the simulation years). The simulated annual GPP fits quite well and only diverges from the observed data by $0.8 \%$ for the calibrated (M2) and 2.6\% for the filter-based (M3) version; simulated respiration by $0.3 \%(\mathrm{M} 2)$ and $0.9 \%$ (M3). The literature-based model version clearly underestimates all ecosystem fluxes. 


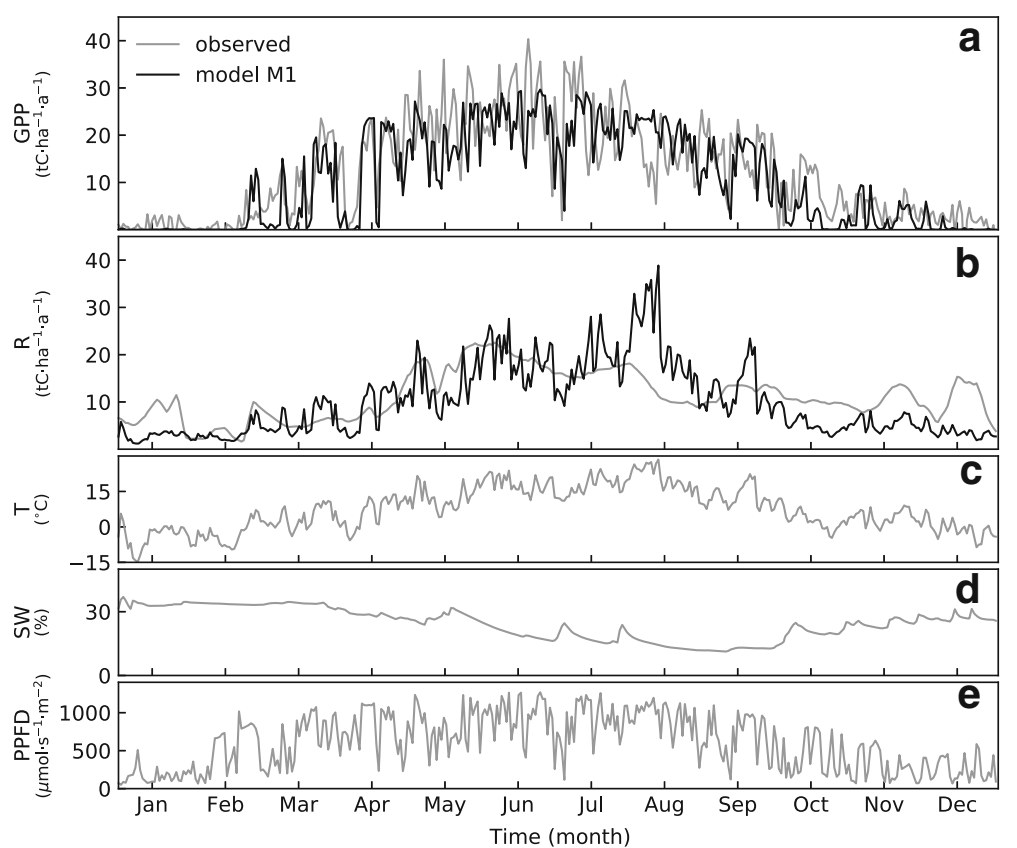

Fig. 1 Time series of the daily observed and simulated data for 2003 at Wetzstein. Observed (grey line) and modeled (M1, black line) (a) GPP and (b) ecosystem respiration (R) of the ecosystem with the literature-based parameterization. Time series of the observed (c) daytime temperature (T), (d) soil water content (SW), and (e) daytime PPFD

\section{Simulation of carbon fluxes at another spruce forest}

We applied the forest model to another spruce forest (Tharandt) for the years 1999-2004 (Fig. 3b). The model parameters were the same as at Wetzstein. Only the climate input and the initialization of the forest model (forest state based on inventory data) were adapted to the site.

Both, the filter-based (M3) and calibrated (M2) model version, performed well for the daily GPP $\left(R^{2}=0.61\right.$ (M2), $R^{2}=0.61(\mathrm{M} 3), \mathrm{RMSE}=8.83 \mathrm{tC} \cdot \mathrm{ha}^{-1} \cdot \mathrm{a}^{-1}(\mathrm{M} 2)$ and RMSE $=9.57 \mathrm{tC} \cdot \mathrm{ha}^{-1} \cdot \mathrm{a}^{-1}(\mathrm{M} 3)$, Table 3). The simulated respiration was even better than at Wetzstein, at the daily scale $\left(R^{2}=0.62\right)$; the NEE performed worse at Tharandt than at Wetzstein $\left(R^{2}=0.38\right)$.

The annual simulated GPP is best for the calibrated (M2) and filter-based (M3) parameterizations (2 and 7\% deviations). In April 2001, the tree density was reduced by $30 \%$ (at Tharandt and in the forest model), which is reflected in the lower GPP values after 2001. In the dry year 2003, the simulated annual GPP is $0.47 \mathrm{tC} \cdot \mathrm{ha}^{-1}$ lower than in the previous year for the calibrated model

Table $3 R^{2}$ and root mean square error (RMSE, in tC $\left.\cdot h a^{-1} \cdot a^{-1}\right)$ at the calibration and validation sites

\begin{tabular}{|c|c|c|c|c|}
\hline & \multicolumn{2}{|c|}{ Wetzstein (calibration site) } & \multicolumn{2}{|c|}{ Tharandt (validation site) } \\
\hline & $\overline{R^{2}}$ & RMSE & $\overline{R^{2}}$ & RMSE \\
\hline \multicolumn{5}{|l|}{ GPP } \\
\hline Lit.-based (M1) & 0.73 & 7.91 & 0.59 & 10.47 \\
\hline Calibrated (M2) & 0.82 & 5.39 & 0.61 & 8.83 \\
\hline Filter-based (M3) & 0.80 & 5.72 & 0.61 & 9.57 \\
\hline \multicolumn{5}{|l|}{ Respiration } \\
\hline Lit.-based (M1) & 0.44 & 6.31 & 0.58 & 5.14 \\
\hline Calibrated (M2) & 0.54 & 4.64 & 0.62 & 4.92 \\
\hline Filter-based (M3) & 0.53 & 4.73 & 0.62 & 5.12 \\
\hline \multicolumn{5}{|l|}{ NEE } \\
\hline Lit.-based (M1) & 0.63 & 6.25 & 0.30 & 7.90 \\
\hline Calibrated (M2) & 0.66 & 5.43 & 0.38 & 6.87 \\
\hline Filter-based (M3) & 0.65 & 5.42 & 0.38 & 7.62 \\
\hline
\end{tabular}



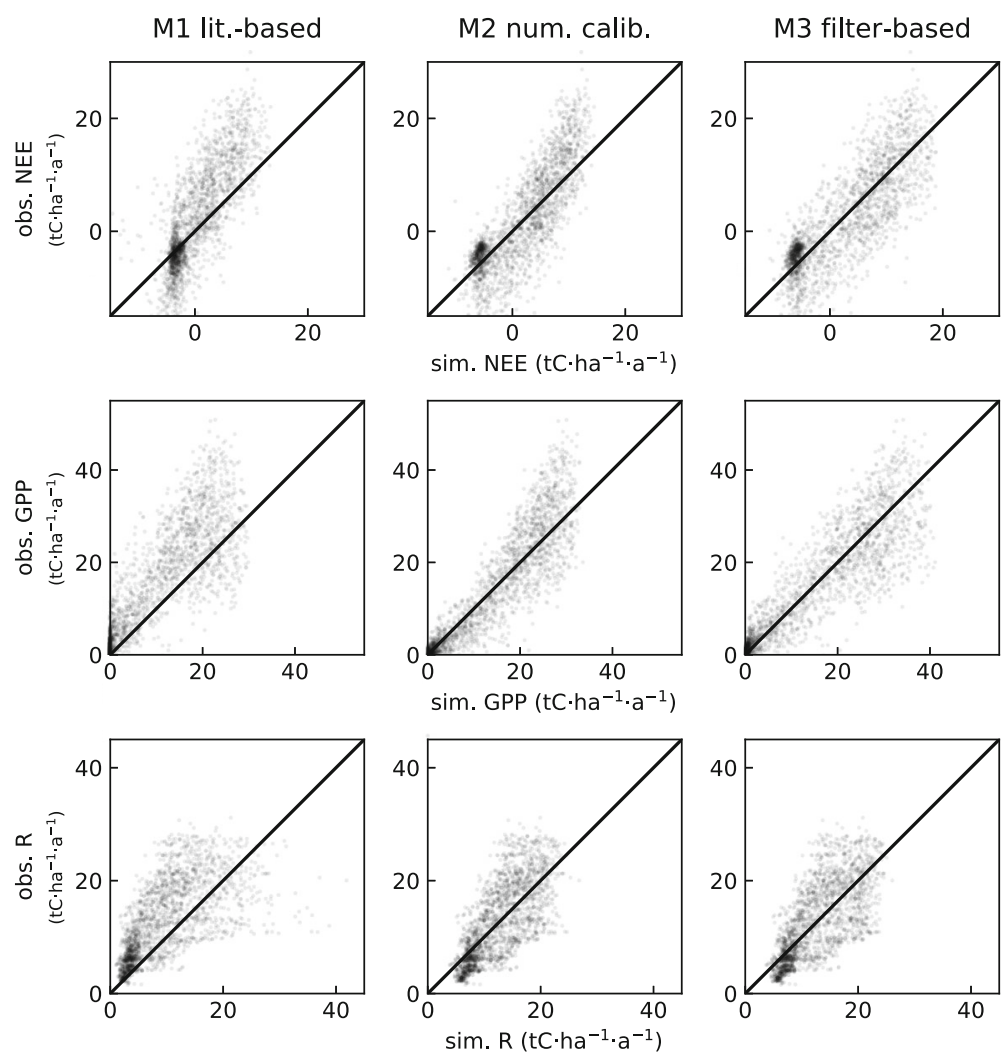

Fig. 2 Simulated vs. observed ecosystem carbon fluxes (NEE, GPP and respiration) at Wetzstein for the three parameterizations for 2192 simulated days

version (M2) and $1.37 \mathrm{tC} \cdot \mathrm{ha}^{-1}$ lower for the filter-based (M3). The observed GPP in 2003 is $1.87 \mathrm{tC} \cdot \mathrm{ha}^{-1}$ lower than in 2002. The annual carbon budget (NEE in Fig. 3bmatches the observed budget well (M2: mean deviation of $20 \%$ from observations; M3: deviation of $16 \%$ ). Note that NEE is the balance between GPP and respiration and the bias is consequently more sensitive. Respiration is partly overestimated for the model versions M2 and M3 (deviations of 14\% and 19\%).

\section{Limiting factors for productivity}

As an example, we analyze here the GPP limitation due to temperature (Fig. 4). Daily GPP values were normalized and filtered for optimal soil water conditions and sunny days to distinguish them from days with other limitations. Filtered, normalized data thus represent the reduction factor due to temperature.

On colder days, the literature-based model (dashed line) shows a reduction in GPP which seemed stronger than the observed. For example, at the freezing point, the observed GPP was reduced to $20 \%$ of its optimum, whereas the model reduced the GPP to nearly 0 . For higher temperatures, the observed data show a reduction of photosynthesis starting at $20{ }^{\circ} \mathrm{C}$, whereas the literature-based parameterization barely showed a reduction in photosynthesis until $30{ }^{\circ} \mathrm{C}$ was reached. For the calibrated model version, the reduction curve showed a steep slope at $0{ }^{\circ} \mathrm{C}$, attained its highest values between $3{ }^{\circ} \mathrm{C}$ and $20^{\circ} \mathrm{C}$ and reached zero at $30{ }^{\circ} \mathrm{C}$. The solid black line shows the best fit of the bell-shaped curve (Eq. 4) through filtered EC-data.

We further analyzed the relationships between the PPFD and productivity, temperature and respiration, as well as the soil water and productivity (see Additional file 1 and Table 1 for the derived filter-based parameter values).

\section{Discussion}

Simulating carbon fluxes at daily and yearly time scales

We analyzed the overall model performance for three parameterizations at the daily scale (Table 3, Fig. 2) and the annual scale (Fig. 3). At the Wetzstein site, the forest model performed best for the numerical calibration. This performance is not surprising since the calibration method aims for the least error (Lehmann and Huth 2015). In any case, it is satisfying that we found a parameter combination that reproduces the observations with such good performance at the daily and annual time scales. This shows that the simplifications assumed in this forest model are sufficient to reproduce the complex interactions of climate and ecosystem fluxes even with the literature-based model version (M1). By comparison, 


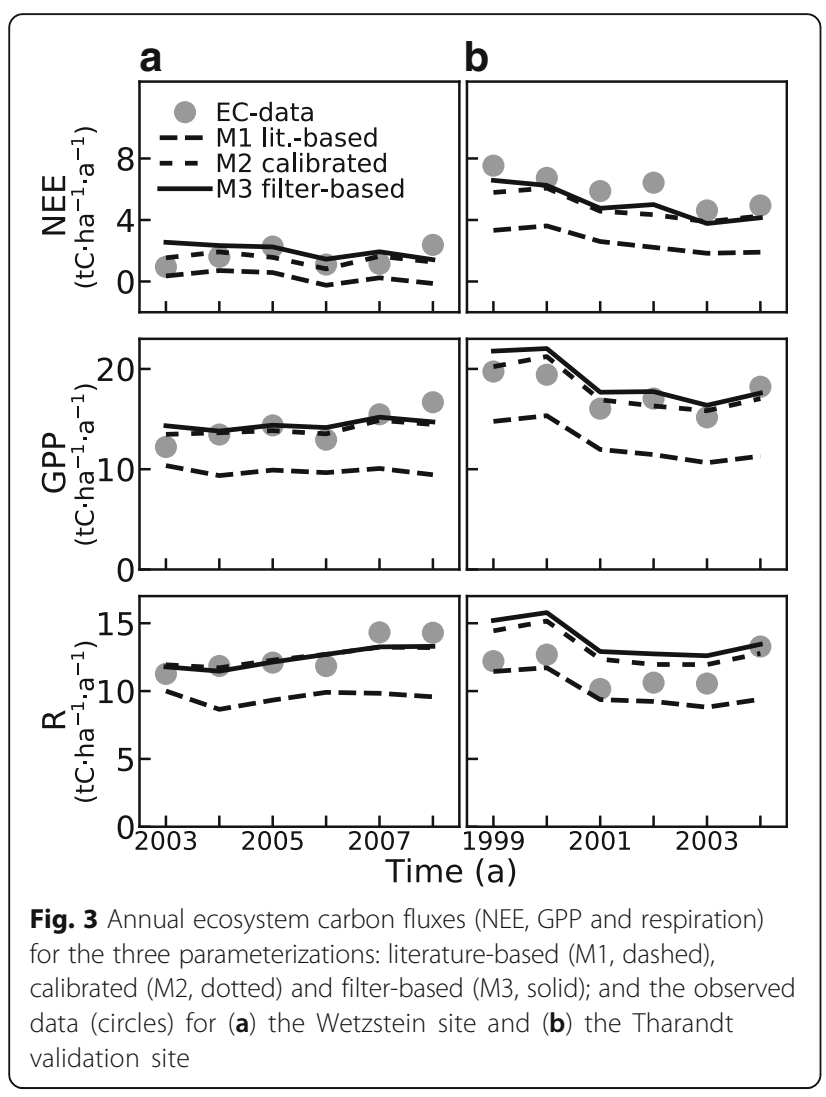

LPJ-Guess simulated daily GPP with a similar performance (RMSE of $6.50-8.94 \mathrm{tC} \cdot \mathrm{ha}^{-1} \cdot \mathrm{a}^{-1}$ and $R^{2}$ of $0.62-$ 0.72) for a pine stand in the Netherlands in a similar study (the range results from different model setups, Vermeulen et al. 2015).

Simulated respiration shows a stronger bias than GPP. The deviation from the observed data can be explained

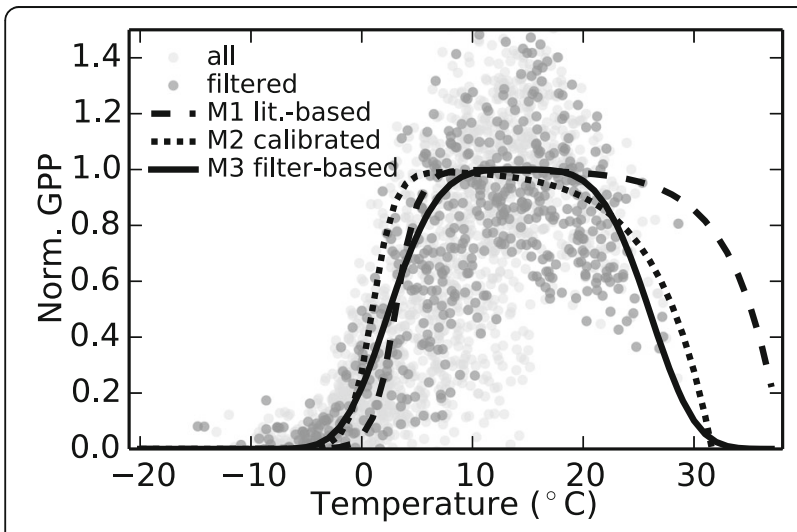

Fig. 4 Temperature limitation of photosynthesis at Wetzstein. Parameter values are listed in Table 2 . The three parameterizations are the literaturebased (dashed) and the calibrated (dotted) parameterizations with the original function Eq. 3), and the filter-based parameterization with the new formulation (Eq.4). The observed, daily mean temperature values of the Wetzstein site were filtered for optimal soil water and light conditions and normalized (see Methods: Observational data and data filtering) in several ways. On the one hand, respiration is strongly coupled to GPP in the forest model. Consequently, strong GPP fluctuations induce strong fluctuations in respiration which is also seen at Tharandt. On the other hand, observed respiration shows a rather smooth curve (Fig. 1b), which is a consequence of the flux-partitioning method that derives respiration from the measured NEE (Reichstein et al. 2005). Respiration data thus arise from a modeling approach. The forest model additionally uses a simplified soil module (as in SEIB-DGVM, Sato et al. 2007). Some of the rhizosphere processes are neglected, such as the release of organic compounds by roots (Nguyen 2009). Rhizomicrobial respiration might have effects on short-term $\mathrm{CO}_{2}$ efflux but should have no effect on the long-term carbon stock in the soil (Kuzyakov 2006). Also, note that different forest histories, such as different forest management at Wetzstein and Tharandt, might thus lead to different soil pools and respiration rates. The fact that the soil carbon pool of the forest model was initialized with a soil pool in a steady state might lead to an overestimation of ecosystem respiration at Tharandt.

The simulation results of Tharandt after the dry year 2003 show that the filter-based version (M3) reproduced the drought and heat event of 2003 better than the calibrated version (M2). Hence, parameter values of individual processes of the filter-based version (M3) might be more appropriate than the calibrated ones (M2) although the overall performance of M2 is better than the performance of M3 (Table 3). This might indicate that the numerical calibration compensates individual processes of extreme events to achieve an overall best performance throughout all simulation years while the filter-based version aims for the best parameterization of individual processes.

The overall performance of all parameterizations let us conclude that carbon fluxes of forest ecosystems can also be modeled with individual-based models. The characteristic of simulating each individual tree has the advantage to investigate in plant-population dynamics, forest structure and their interaction with carbon dynamics in future studies.

\section{Analyzing limiting factors for productivity with the help of EC data}

To test whether the parameter values (M1, M2) correctly describe the limiting factors of photosynthesis and respiration in the forest model, we filtered the EC data. The filtering singled out time steps that are mainly influenced by a single constraint such as temperature or water stress. This approach resulted in an additional parameterization of the forest model for which the functional relations between the variable climate and model processes were directly fitted through the filtered data 
(M3). As an example, we here discuss the relationship between temperature and productivity. The other relationships are discussed in detail in the Additional file 1.

The relationship between the measured GPP and temperature (Fig. 4) showed that the literature-based parameterization, which was validated for long-term simulations (Bohn et al. 2014), underestimated GPP for low and overestimated it for high temperatures. The function was taken from the LPJ model (Sitch et al. 2003). In LPJ, the function was applied as a "bulk" temperature-response function for different plant functional types in temperate forests to reproduce the current vegetation distribution (Stephan Sitch, personal communication). In FORMIND, this function seems to be sufficient to estimate the current mean carbon budgets from long-term simulations (Bohn et al. 2014), but the model version is not able to display inter-annual changes correctly. A similar study that tested the temperature-response curve in LPJ-Guess in a pine stand concluded that the curve needs to be shifted to lower temperatures (Vermeulen et al. 2015). This finding also agrees with the fact that trees can photosynthesize down to a temperature of about $-5{ }^{\circ} \mathrm{C}$ (root zone temperature), while growth seems to stop at approximately $0{ }^{\circ} \mathrm{C}$ (Körner and Paulsen 2004). The numerical calibration experiment also shows that shifting the curve towards lower temperatures results in a better fit to the observed data. The EC data indicate photosynthetic activity down to about $-10{ }^{\circ} \mathrm{C}$. This is plausible considering that the air temperature is generally lower than temperature in the root zone during winter. In addition, the trees at the Wetzstein site are adapted to low temperatures and cold winter conditions due to the elevation. Note, that positive ecosystem GPP does not necessarily implicate tree growth since respiration compensates for GPP at low temperatures and low PPFD in the forest model.

GPP was not limited due to high temperatures with the literature-based parameterization (M1). High temperatures might go along with a vapor pressure deficit limitation (Körner 1994; Lasslop et al. 2010), which is not considered in our model approach. This assumption is supported by the results of the numerical calibration (the limiting factor is 0 at $31.6{ }^{\circ} \mathrm{C}$ ). This reduction in temperature might compensate for the missing vapor pressure deficit limitation.

Since the original reduction curve did not fit the filtered data, we introduced a new functional relationship for the temperature reduction factor (Eq. 4, methods). The new curve originates from a normal distribution that describes the temperature dependence of the photosynthetic electron transport rate (June et al. 2004). A completely normal distribution $(n=2)$ led to a very small plateau in the temperature reduction function, which means a small range of optimal temperature conditions. $n=4$ led to a much wider range of optimal conditions. An advantage of the introduced function is that it uses only two instead of four parameters. We therefore suggest using the less complex bell-shaped curve for future studies.

The fact that the original temperature curve could not be fitted through filtered data properly supports the assumption that a pure calibration against ecosystem fluxes does not necessarily result in optimal parameter values of the individual model processes. We can conclude that eddy covariance data and the filtering-approach can give important insights into the correct parameterization of model processes (the limiting factors).

\section{Sources of uncertainty}

This study comes with a variety of uncertainties from various sources that must be considered. The first source of uncertainty comes from the EC data. NEE is measured at a half-hourly scale. However, it comes with data gaps that are filled to compare the observed data with the simulated data at a daily time scale. The gap-filled NEE is based on a modeling procedure (Reichstein et al. 2005). At the Tharandt site, for example, the uncertainty of the gap filling methods is up to $10 \%$ (Grünwald and Bernhofer 2007). In addition, GPP and respiration are not directly measured, but are partitioned from the NEE, which is based on another modeling procedure (Reichstein et al. 2005). When we analyzed the drought event of 2003 at Tharandt, we found that GPP was $1.87 \mathrm{tC}^{\mathrm{h}} \mathrm{ha}^{-1}$ less than in the previous year. A multi-site study on the event in 2003 reported a reduction of 2.08 tC.ha ${ }^{-1}$ at Tharandt (Ciais et al. 2005). These deviations demonstrate the uncertainties implied by gap filling and the partitioning of EC data, especially at the annual time scale.

The second potential source of uncertainties comes from the filtering method and the concept of limiting factors. The forest model, and thus also the filtering method, consider only temperature and water as limiting factors. The vapor pressure deficit and its influence on productivity (as in BIOME-BGC, Kimball et al. 1997; 3PG, Landsberg and Waring 1997), for example, is not considered. However, we still assume that the filtered data are reasonable for singling out different constraints in forest productivity.

\section{Conclusion}

The model version only based on literature values (M1, Bohn et al. 2014) is capable of reproducing the seasonal cycle and daily fluctuations of carbon fluxes. However, this model version underestimates carbon fluxes at both spruce stands on the annual time scale. The calibrated model version (M2) derived from a numerical calibration (Lehmann and Huth 2015) against the observed NEE, GPP and respiration performs best at the daily and 
annual time scales. Deviations of the individual processes from the observed data seem to compensate each other, so that, in sum, they reproduce the observed net fluxes well. The third parameterization resulted from a fit through filtered data (M3). We identified a new functional relationship between temperature and GPP. Its mean performance at both sites differs only slightly from the calibrated parameterization, but it shows a closer match to observations for the extreme event at Tharandt in 2003. This shows that we should not blindly trust in a numerical calibration, although its overall performance is best.

The presented filter method improved carbon flux estimates for both spruce stands by improving the model processes. The consideration of the individual limiting factors for productivity (Fig. 4, Additional file 1: App. 1) is essential to correctly reveal the impact of inter-annual climate variations on carbon fluxes. Therefore, we favor the filter-based model version for future studies. We can conclude that an individual-based forest model is a valuable tool that allows analyses of daily and yearly carbon fluxes in addition to the traditional analyses of forest successions and biomass.

\section{Additional file}

Additional file 1: Simulation results for the three parameterizations. (DOCX $826 \mathrm{~kb}$ )

\section{Abbreviations}

EC: Eddy covariance; GPP: Gross primary productions; NEE: Net ecosystem exchange; PPFD: Photosynthetic photon flux density; R: Ecosystem respiration; RMSE: Root mean square error; SW: Soil water

\begin{abstract}
Acknowledgements
Measurements were supported by the CarboEurope-IP (European Commission, Directorate-General Research, Sixth Framework Programme, Priority 1.1.6.3: Global Change and Ecosystem (Contract No. GOCECT-2003-505572)) of the Max Planck Institute for Biogeochemistry in Jena. We thank Martina Mund of the Georg-August-University of Göttingen for the inventory information at the Wetzstein site. EC data at the Tharandt site were kindly provided by the Department of Meteorology at TU Dresden. We thank Rico Fischer, Sebastian Paulick and Franziska Taubert for their support and discussions.
\end{abstract}

\section{Funding}

ER, FB and AH were supported by the Helmholtz-Alliance Remote Sensing and Earth System Dynamics. ER was supported by the Helmholtz Impulse and Networking Fund through the Helmholtz Interdisciplinary Graduate School for Environmental Research (HIGRADE).

\section{Availability of data and materials}

Simulation results are presented as additional supporting files. The forest model FORMIND is freely available on www.formind.org.

\section{Authors' contributions}

$\mathrm{ER}, \mathrm{AH}, \mathrm{MC}$ worked together in designing this manuscript. FB and ER worked together on the parameterization of the forest model. CR processed the eddy covariance data. All authors were involved in the writing process. ER coordinated their contributions and led the writing. All authors read and approved the final manuscript.

\section{Competing interests}

The authors declare that they have no competing interests.
Consent for publication

Not applicable.

Ethics approval and consent to participate

Not applicable.

\section{Author details}

${ }^{1}$ UFZ - Helmholtz Centre for Environmental Research, Permoserstr. 15, 04318 Leipzig, Germany. ${ }^{2}$ University of Osnabrück, Barbarastraße 12, 49076 Osnabrück, Germany. ${ }^{3}$ German Centre for Integrative Biodiversity Research (iDiv) Halle-Jena-Leipzig, Deutscher Platz 5e, 04103 Leipzig, Germany. ${ }^{4}$ INRA-Université de Lorraine, UMR1137 Ecologie et Ecophysiologie

Forestières, 54280 Champenoux, France.

Received: 1 November 2016 Accepted: 10 April 2017

Published online: 27 April 2017

\section{References}

Aubinet M, Grelle A, Ibrom A, Rannik Ü, Moncrieff J, Foken T, Kowalski AS, Martin PH, Berbigier P, Bernhofer C, Clement R, Elbers J, Granier A, Grünwald T, Morgenstern K, Pilegaard K, Rebmann C, Snijders W, Valentini RM, Vesala T (1999) Estimates of the Annual Net Carbon and Water Exchange of Forests: The EUROFLUX Methodology. Adv. Ecol. Res. pp 113-175. https://doi.org/10. 1016/50065-2504(08)60018-5

Bohn FJ, Frank K, Huth A (2014) Of climate and its resulting tree growth: Simulating the productivity of temperate forests. Ecol Modell 278:9-17. doi:10.1016/j. ecolmodel.2014.01.021

Botkin DB, Janak JF, Wallis JR (1972) Some ecological consequences of a computer model of forest growth. J Ecol 60:849. doi:10.2307/2258570

Bugmann H (2001) A review of forest Gap models. Clim Change 51:259-305

Ciais P, Reichstein M, Viovy N, Granier A, Ogée J, Allard V, Aubinet M, Buchmann $N$, Bernhofer C, Carrara A, Chevallier F, De Noblet N, Friend AD, Friedlingstein P, Grünwald T, Heinesch B, Keronen P, Knohl A, Krinner G, Loustau D, Manca G, Matteucci G, Miglietta F, Ourcival JM, Papale D, Pilegaard K, Rambal S, Seufert G, Soussana JF, Sanz MJ, Schulze ED, Vesala T, Valentini R (2005) Europe-wide reduction in primary productivity caused by the heat and drought in 2003. Nature 437:529-33. doi:10.1038/nature03972

Fischer R, Armstrong A, Shugart HH, Huth A (2014) Simulating the impacts of reduced rainfall on carbon stocks and net ecosystem exchange in a tropical forest. Environ Model Softw 52:200-206. doi:10.1016/j.envsoft.2013.10.026

Fischer R, Bohn F, Dantas de Paula M, Dislich C, Groeneveld J, Gutiérrez AG, Kazmierczak M, Knapp N, Lehmann S, Paulick S, Pütz S, Rödig E, Taubert F, Köhler P, Huth A (2016) Lessons learned from applying a forest gap model to understand ecosystem and carbon dynamics of complex tropical forests. Ecol Modell 326:124-133. doi:10.1016/j.ecolmodel.2015.11.018

Granier A, Bréda N, Biron P, Villette S (1999) A lumped water balance model to evaluate duration and intensity of drought constraints in forest stands. Ecol Modell 116:269-283. doi:10.1016/\$0304-3800(98)00205-1

Granier A, Reichstein M, Bréda N, Janssens IA, Falge E, Ciais P, Grünwald T, Aubinet M, Berbigier P, Bernhofer C, Buchmann N, Facini O, Grassi G, Heinesch B, Ilvesniemi H, Keronen P, Knohl A, Köstner B, Lagergren F, Lindroth A, Longdoz B, Loustau D, Mateus J, Montagnani L, Nys C, Moors E, Papale D, Peiffer M, Pilegaard K, Pita G, Pumpanen J, Rambal S, Rebmann C Rodrigues A, Seufert G, Tenhunen J, Vesala T, Wang Q (2007) Evidence for soil water control on carbon and water dynamics in European forests during the extremely dry year: 2003. Agric For Meteorol 123:123-145. doi:10.1016/j. agrformet.2006.12.004

Grünwald T, Bernhofer C (2007) A decade of carbon, water and energy flux measurements of an old spruce forest at the Anchor Station Tharandt. Tellus B 59:387-396. doi:10.1111/j.1600-0889.2007.00259.x

Gutiérrez AG, Armesto JJ, Aravena J-C, Carmona M, Carrasco NV, Christie DA, Peña M-P, Pérez C, Huth A (2009) Structural and environmental characterization of old-growth temperate rainforests of northern Chiloé Island, Chile: Regional and global relevance. For Ecol Manage 258:376-388. doi:10.1016/.joreco.2009.03.011

Gutiérrez AG, Armesto JJ, Díaz MF, Huth A (2012) Sensitivity of North Patagonian temperate rainforests to changes in rainfall regimes: a process-based, dynamic forest model. Biogeosciences Discuss 9:6293-6333. doi:10.5194/bgd-9-6293-2012

Huth A, Ditzer T (2000) Simulation of the growth of a lowland Dipterocarp rain forest with FORMIX3. Ecol Modell 134:1-25. doi:10.1016/50304-3800(00)00328-8 
June T, Evans JR, Farquhar GD (2004) A simple new equation for the reversible temperature dependence of photosynthetic electron transport: a study on soybean leaf. Funct Plant Biol 31:275-283. doi:10.1071/FP03250

Keenan TF, Baker I, Barr A, Ciais P, Davis K, Dietze M, Dragoni D, Gough CM, Grant R, Hollinger D, Hufkens K, Poulter B, Mccaughey H, Raczka B, Ryu Y, Schaefer K, Tian H, Verbeeck H, Zhao M, Richardson AD (2012) Terrestrial biosphere model performance for inter-annual variability of land-atmosphere CO 2 exchange. Glob Chang Biol 18:1971-1987. doi:10.1111/j.1365-2486.2012.02678.x

Kimball JS, White MA, Running SW (1997) BIOME-BGC simulations of stand hydrologic processes for BOREAS. J Geophys Res 102:29043

Köhler P, Huth A (2004) Simulating growth dynamics in a South-East Asian rainforest threatened by recruitment shortage and tree harvesting. Clim Change 67:95-117. doi:10.1007/s10584-004-0713-9

Köhler P, Huth A (1998) The effects of tree species grouping in tropical rainforest modelling: Simulations with the individual-based model Formind. Ecol Modell 109:301-321. doi:10.1016/S0304-3800(98)00066-0

Körner C (1994) Leaf Diffusive Conductances in the Major Vegetation Types of the Globe. In: Schulze E-D, Caldwell MM (eds) Ecophysiology of Photosynthesis. Springer Berlin Heidelberg, Berlin, Heidelberg

Körner C, Paulsen J (2004) A world-wide study of high altitude treeline temperatures. J Biogeogr 31:713-732. doi:10.1111/j.1365-2699.2003.01043.x

Kuzyakov Y (2006) Sources of CO2 efflux from soil and review of partitioning methods. Soil Biol Biochem 38:425-448. doi:10.1016/j.soilbio.2005.08.020

Landsberg JJ, Waring RH (1997) A generalised model of forest productivity using simplified concepts ofradiation-use efficiency, carbon balance and partltlonlng For Ecol Manage 95:209-228. doi:10.1016/S0378-1127(97)00026-1

Lasslop G, Reichstein M, Papale D, Richardson AD, Arneth A, Barr A, Stoy P, Wohlfahrt G (2010) Separation of net ecosystem exchange into assimilation and respiration using a light response curve approach: critical issues and global evaluation. Glob Chang Biol 16:187-208. doi:10.1111/j.1365-2486.2009.02041.x

Lehmann S, Huth A (2015) Fast calibration of a dynamic vegetation model with minimum observation data. Ecol Modell 301:98-105. doi:10.1016/j.ecolmodel. 2015.01.013

Maidment D (1993) Handbook of hydrology. McGrawHill Inc, New York

Meehl GA, Tebaldi C (2004) More intense, more frequent, and longer lasting heat waves in the 21st century. Science 305:994-997. doi:10.1126/science.1098704

Nguyen C (2009) Rhizodeposition of Organic C by Plant: Mechanisms and Controls. In: Sustainable Agriculture. Springer Netherlands, Dordrecht, pp 97-123

Pacala SW, Canham CD, Silander Jr JA (1993) Forest models defined by field measurements: I. The design of a northeastern forest simulator. Can J For Res 23:1980-1988. doi:10.1139/x93-249

Piao S, Luyssaert S, Ciais P, Janssens IA, Chen A, Cao C, Fang J, Friedlingstein P, Luo Y, Wang S (2010) Forest annual carbon cost: a global-scale analysis of autotrophic respiration. Ecology 91:652-661

Prentice IC, Sykes MT, Cramer W (1993) A simulation model for the transient effects of climate change on forest landscapes. Ecol Modell 65:51-70. doi:10. 1016/0304-3800(93)90126-D

Rebmann C, Zeri M, Lasslop G, Mund M, Kolle O, Schulze E-D, Feigenwinter C (2010) Treatment and assessment of the CO2-exchange at a complex forest site in Thuringia, Germany. Agric For Meteorol 150:684-691. doi:10.1016/j. agrformet.2009.11.001

Reichstein M, Falge E, Baldocchi D, Papale D, Aubinet M, Berbigier P, Bernhofer C, Buchmann N, Gilmanov T, Granier A, Grunwald T, Havrankova K, Ilvesniemi H, Janous D, Knohl A, Laurila T, Lohila A, Loustau D, Matteucci G, Meyers T, Miglietta F, Ourcival J-M, Pumpanen J, Rambal S, Rotenberg E, Sanz M, Tenhunen J, Seufert G, Vaccari F, Vesala T, Yakir D, Valentini R (2005) On the separation of net ecosystem exchange into assimilation and ecosystem respiration: review and improved algorithm. Glob Chang Biol 11:1424-1439. doi:10.1111/j.1365-2486.2005.001002.x

Sato H, Itoh A, Kohyama T (2007) SEIB-DGVM: A new Dynamic Global Vegetation Model using a spatially explicit individual-based approach. Ecol Modell 200: 279-307. doi:10.1016/j.ecolmodel.2006.09.006

Shugart HH (1984) A Theory of Forest Dynamics. The Blackburn Press, New Jersey

Sitch S, Smith B, Prentice IC, Arneth A, Bondeau A, Cramer W, Kaplan JO, Levis S, Lucht W, Sykes MT, Thonicke K, Venevsky S (2003) Evaluation of ecosystem dynamics, plant geography and terrestrial carbon cycling in the LPJ dynamic global vegetation model. Glob Chang Biol 9:161-185. doi:10.1046/j.13652486.2003.00569.x
Smith B, Prentice IC, Sykes MT (2001) Representation of vegetation dynamics in the modelling of terrestrial ecosystems: comparing two contrasting approaches within European climate space. Glob Ecol Biogeogr 10:621-637. doi:10.1046/j.1466-822X.2001.t01-1-00256

Sonntag M (1998) Klimaveraenderung und Waldwachstum: TREEDYN3Simulationen mit einer Analyse modellstruktureller Unsicherheiten. PhD thesis. Universitaet Gesamthochschule Kassel.

Thornley JHM, Johnson IR (1990) Plant and crop modelling: a mathematical approach to plant and crop physiology. Oxford University Press. https://doi. org/10.1016/0308-521X(91)90064-H

Vermeulen MH, Kruijt B, Kabat P (2015) Modelling short term variability in carbon and water exchange in a Dutch pine forest. Earth Syst Dyn 14:5575. doi:10. 5194/esd-6-485-2015

Zaitchik BF, Macalady AK, Bonneau LR, Smith RB (2006) Europe's 2003 heat wave: A satellite view of impacts and land - Atmosphere feedbacks. Int J Climatol 26:743-769. doi:10.1002/joc.1280

\section{Submit your manuscript to a SpringerOpen ${ }^{\mathcal{O}}$ journal and benefit from:}

- Convenient online submission

- Rigorous peer review

- Immediate publication on acceptance

- Open access: articles freely available online

- High visibility within the field

- Retaining the copyright to your article

Submit your next manuscript at $>$ springeropen.com 